\title{
Research and Analysis about the Problems of Curriculum Setting under the Credit System
}

\author{
Yongju LI \\ Office of Academic Affairs of Leshan Normal university, Sichuan, China \\ Hui WANG \\ College of Mathematics Science of Chongqing Normal university, Chongqing, China
}

\begin{abstract}
This paper analyzed the related problems of curriculum setting basing on the management mode of credit system teaching. The article also discussed the root of the problem and given some reasonable suggestions. It provided reference basis for the professional construction and curriculum setting. It can promote the construction of Characteristic and emerging subject.
\end{abstract}

KEYWORD: The credit system; curriculum setting; training scheme; selective course

\section{INTRODUCTION}

Curriculum is a general term for each subject and various education activities which is constructed by school according to certain educational purpose [1]. Curriculum is the floorboard of subjects, status and sequence included in the teaching plan [2]. From these different curriculum definition and description, it can be seen that the curriculum is organized around specific target. This is the goal of training plan target, and it is also the stage goal of the curriculum which should be completed in the whole course system structure. The curriculum is the problem for each different levels schools have to face. It is particularly prominent obviously in colleges and universities because of different Characteristics and professional.

\section{ABOUT THE CREDIT SYSTEM}

The credit system from American brings new vitality for Chinese Education and it makes a significant contribution to promote the teaching reform of our country. The first university who adapt the credit system is Peking University in China. Under the leadership of Peking University, many universities have adopted this mode. But the credit system was replaced completely by the academic year system after the founding of new China [3]. Until the $70 \mathrm{~s}$, colleges and universities began to restore credit system. Affected by various conditions, most of colleges and universities actually adopt the academic year system and credit system together which is called the "credit and year" system.

Under the new system, there are many changes in the curriculum compared with the academic year system. If we don't make a corresponding change in the credit system following the old teaching system of curriculum design, the training goal must be failure. Fortunately, many universities have realized this. They constantly study and explored a new plan of curriculum design. It is discussed on the problems have appeared in the curriculum reform in the following text.

\section{THE PROBLEMS TO RESOLVE OF CURRICULUM SETTING UNDER THE CREDIT SYSTEM}

Colleges and universities teaching and management also met a lot of new problems basing on the credit system. And these problems may directly affect the implementation of the training scheme and the realization of training objectives. Such as:

\subsection{The problem of parallel course setting headings}

The credit system is more flexible than the academic year system in many ways. The course setting is also a very challenging problem. Students can choose courses and teachers independently [4]. In order to achieve this goal, we must design many parallel curriculums according to the training plans and training objectives. This has brought the difficulty for curriculum design. Because the curriculum itself is also a worldwide difficult problem and curriculum reform is a key and difficulty point in the research of modern education reform. For most of colleges and universities, there is no professional personnel 
engaged in the scientific research. Besides this job is too professional, and it is a complicated and systematic project. Therefore, in practice, many colleges and universities still continue to use some of the major education under the academic year system of curriculum [4]. All though there exists constant innovation, development and change, but there obviously exists irrationality of curriculum. That would cause even adopt credit system, but the course provided is very limited. These course almost have become compulsory course. From this point of view, this year-system and the management system is not much difference, and it can better reflect the advantage of the credit system. So we need to put in more manpower and material resources in the curriculum. Although we can't provide professional researchers for each curriculum, we can make full use of the existing resources. For example, fully mobilize the enthusiasm of teachers under the leading of director of teaching and research section. We can encourage various professional teachers to research of the corresponding professional curriculum goal and curriculum by using reasonable competition and incentives. This can ultimately made the professional curriculum setting scientific more and more. It also makes each professional development also more in line with the national development and the needs of the social reality. And students can also learn to use.

\subsection{The blindness problem of course selection}

Course-selecting is the key of the credit system for students. There must exist course-selecting in college or university who adopts the credit system [6]. The student is required to choose the course which should be completed in the next semester. But from the actual selection condition, a lot of students have great blindness in their course selection. Because the courses for selection are never learned. The students do not understand of the course also. And the courseselecting always begin at the end of the term. So it brings student hurry to complete selection. Most of the students will not take the initiative to study on training programs and training goal. So student often completes course-selecting hurried and confused and blinded. The blindness problem of course selection can bring many problems in the future. Such as interest, difficulty and etc. will appear inevitably.

In order to reduce the blindness of student's course selection, the curriculum must be scientific. The number of courses to select should not be too large. And students must be introduced the course system and training goal clearly. Teaches should give some advice for the course system. Learning guidance and professional curriculum system should be introduced in the newborn Education. We should make the students understand themselves what level they should reach after graduation during the period of university through their own professional learning. And the detailed phase objectives must be given at each stage. So the student can contrast with himself in each stage of time. We also list the important curriculum one by one, and give some guidance and advice. So Students will be able to have a preliminary understanding to their future learning in advance. And they will pay attention to every stage of optional courses actively. With these preparations and foundation, students will select courses independently. So the blindness problem of course selection will be solved.

\subsection{The problem of minor courses setting}

Minor system is an aspect of flexible credit system. Most colleges and Universities under the credit system also allow students to choose the other professional courses. So that students have the opportunity to obtain a certificate from the two major at the time of graduation to broaden the field of employment. Considering the students' learning focus mainly on the first professional, because the first professional courses tend to be very rich and comprehensive, it is obviously not too realistic that these courses are open to other professional student. Students do not have so much energy to complete the professional course learning. And the teaching resources can't meet the requirement of the curriculum arrangement. In order to ensure that students are able to master the second professional (minor professional) major knowledge and skills, the main course should be picked for other professional students to choose in the course design but not all the course. That is to say the minor courses should be capable of embodying the professional elite, rather than trying to be all. At the same time, this must be able to reach the professional most basic credit requirements. This requires college or university have a very comprehensive grasp in the specialty structure, curriculum system, training programs and the goal.

\subsection{The problem of controlling the number of the course}

Another aspect of credit system flexibility is that students can independently choose different number of course to study. As long as they can complete the required credits they can graduate. That is to say the students can select multiple courses to study each semester according to their own characteristics, so they can graduation in advance. And they can also be appropriate to have fewer choices of some courses, and make the learning time become longer to postpone the graduation time, so as to meet the need of the work, the body and learning. How many courses to choice is suitable? It is grasped by students themselves. Some students especially the fresher may 
not estimate their own learning ability and schedule fully. They select too many courses to study. His study later can't meet the requirements. Because the result is not qualified to obtain credit in the final exam, they have to face the embarrassing situation of make-up or rebuild. The make-up and repair records are often recorded in to their archives. When the bad record reached a certain limit, it will affect their normal graduating or getting a degree. It has played a reaction. In addition, some students are lazy, and they may select too few courses to study easily. Finally they found the credit is not enough to graduation. So they have to follow the next students to finish owed credit and postpone graduation. According to incomplete statistics, about $5 \%$ of fresher will encounter this kind of trouble.

In order to avoid the occurrence of the two extreme cases, we should average the credit to each semester according the curriculum structure when we set the curriculum. Especial in the last semester, students have to write graduation thesis, practice, advance appointment etc. Considering these factors, we can give the students some guidance and recommendations. We should begin to intervene early when finding the number of selecting course is too large or small. We should get the reason for selection and suggest the student to adjust the number of selection if there is exists any blindness. This can help the student to reduce the risk of unable to complete their studies in normal.

\subsection{The problem of balance between optional courses}

If the school adopted the management mode of credit system, there must exist compulsory course and optional course at the same time [6] That is to say to finish study, the backbone courses often is defined as a required course. And these courses are the compulsory course. The rest courses are defined as optional courses. As long as some course are selected to complete the credits, that is enough. The choice of teacher is together with the choice of the course. This system is accompanied by the credit system as an incentive mechanism to improve the teachers' teaching quality. This has also brought another drawback. Most of students are not familiar with the teachers for selection. It is possible for them to not adapt the teacher's teaching style. This will bring some problem for later learning. In addition, there are some students' motivation exists some problems.
They always choose those courses to easily pass. Some meaningful but more difficult courses are lack of choice. This may lead to the distance of the cultivation of students' comprehensive abilities of the target more and more far. These problems will soon back to the curriculum. Then the curriculum should be adjusted in real time and the minor courses have to be upgrade at any time. The difficult and distinguish for the minor course should be adjust soon. In addition, the monitoring mechanism is also used in the teaching process. We can assessment and guidance teachers' teaching quality and teaching attitude, teachers' moral and so on. As far as possible, we try to make each minor course and each teacher under the same threshold for students to choose. So the quality of courses and learning can be achieved.

\section{THE CONCLUSION}

The curriculum itself is a problem of recognized and colleges and universities generally don't have such a full-time researchers. The reform of college education is more and more fast, the emerging and characteristic professional emerges constantly. This requires colleges and universities must put more energy to curriculum research and constantly reference from the existing curriculum experiences and lessons.

\section{REFERENCES}

[1] Qiming Zheng, Tiangxiang Cai. Higher education. East China Normal University publishing house. 1988: 122-125 (in Chinese)

[2] Maoyuan Pan, Wei Wang. Higher education. Fujian Education Publishing House. 1995: 204-220 (in Chinese)

[3] Qiaoxia Zhou. The credit system management-core course selection system. Journal of Ningbo University (Educational Science Edition). 2002 (6): 35-36 (in Chinese)

[4] Yuanzhi Zhang, Baiming Sun, Wei Zhu. The investigate about the problem of course-selection under the credit system and flexible system. Education Forum. 2009 (12): 69-70 (in Chinese)

[5] Xianjin Cai. The theory and practice of the credit system in University. Ocean University of China publishing house. 2006. 7: 180-182 (in Chinese)

[6] Hailong Sun. The theory and practice of the credit system. The Wuyi University Journal (Social Science Edition). 1996 (1): $28-29$ 